\title{
Hepatoprotective Effects of Flavonoids from Shekwasha (Citrus depressa) against D-Galactosamine-Induced Liver Injury in Rats
}

\author{
Toshiyuki AKACHI ${ }^{1,4}$, Yasuyuki SHIINA ${ }^{2}$, Yayoi OHISHI ${ }^{2}$, Takumi KAWAGUCHI ${ }^{2}$, \\ Hirokazu KAWAGISHI ${ }^{3}$, Tatsuya MORITA ${ }^{2}$, Makoto MORI ${ }^{2}$ and Kimio SUGIYAMA ${ }^{2, *}$ \\ ${ }^{1}$ The United Graduate School of Agricultural Science, Gifu University, 1-1 Yanagido, Gifu 501-1193, Japan \\ ${ }^{2}$ Department of Applied Biological Chemistry, Faculty of Agriculture, Shizuoka University, 836 Ohya, \\ Shizuoka 422-8529, Japan \\ ${ }^{3}$ Graduate School of Science and Technology, Shizuoka University, 836 Ohya, Shizuoka 422-8529, Japan \\ ${ }^{4}$ Central Laboratories, Daiwa Can Company, 5-5-1 Nishihashimoto, Sagamihara 229-1183, Japan
}

(Received October 19, 2009)

\begin{abstract}
Summary We attempted to isolate the constituent(s) responsible for the suppressive effect of the juice of shekwasha, a citrus produced in Okinawa Prefecture, on D-galactosamine (GalN)-induced liver injury in rats. Liver injury-suppressive activity, as assessed by plasma alanine aminotransferase and aspartate aminotransferase activities, was found only in the fraction that was extracted with $n$-hexane when three fractions were added to the diet and fed to rats. Of five compounds isolated from the $n$-hexane-soluble fraction by silica gel column chromatography, three compounds had liver injury-suppressive effects when five compounds were singly force-fed to rats at a level of $300 \mathrm{mg} / \mathrm{kg}$ body wt $4 \mathrm{~h}$ before the injection with GalN. The structures of the three active compounds were determined as $3^{\prime}, 4^{\prime}, 5,6,7,8$ hexamethoxyflavanone (citromitin), 4',5,6,7,8-pentamethoxyflavone (tangeretin) and $3^{\prime}, 4^{\prime}, 5,6,7,8$-hexamethoxyflavone (nobiletin), which are known flavonoids mainly existing in citrus. Nobiletin, the most important compound in the n-hexane-soluble fraction, also had suppressive effects on liver injuries induced by carbon tetrachloride, acetaminophen and GalN/lipopolysaccharide (LPS) in addition to liver injury induced GalN. Nobiletin suppressed GalN/LPS-induced increases in plasma tumor necrosis factor (TNF)- $\alpha$ and nitric oxide (NO) concentrations and hepatic mRNA levels for inducible NO synthase and DNA fragmentation. These results suggest that nobiletin suppressed GalN/LPS-induced liver injury at least by suppressing the production of both TNF- $\alpha$ and NO. The results obtained here indicate that the hepatoprotective effect of shekwasha juice is mainly ascribed to several polymethoxy flavonoids included in the juice.
\end{abstract}

Key Words D-galactosamine, liver injury, shekwasha, Citrus depressa, flavonoids

Fruits and vegetables are important as sources of several nutrients such as vitamins, minerals and dietary fibers. Fruits and vegetables also contain a variety of constituents, which are characteristic of the species of plant. It is widely recognized that relatively high intakes of fruits and vegetables are desirable for prevention of diseases and maintenance of healthy conditions (1). Previously we reported that several kinds of fruit had suppressive effects on D-galactosamine (GalN)-induced liver injury in rats when various kinds of lyophilized fruit were added to the diet (2). Furthermore, recently we found that some fruit juices, e.g., camu-camu and shekwasha, also had suppressive effects on GalNinduced liver injury in rats, and we identified the active compound (unpublished data). These findings indicate that certain fruits (and possibly vegetables) have a hepatoprotective effect in addition to nutritional effects.

*To whom correspondence should be addressed.

E-mail: acksugi@agr.shizuoka.ac.jp
Since the liver is the central organ of many types of metabolism, the hepatoprotective effect of foods is worthwhile to investigate in detail, not only from the viewpoint of food science but also from the viewpoint of nutrition.

In the present study, we attempted to isolate the constituent(s) responsible for the hepatoprotective effect of shekwasha, a citrus produced mainly in Okinawa Prefecture, since shekwasha had a relatively potent suppressive effect on GalN-induced liver injury in our earlier study. We also investigated the effects of nobiletin, a major active compound of shekwasha, on some other types of liver injury, i.e., liver injuries induced by carbon tetrachloride, acetaminophen (APAP) and GalN/ lipopolysaccharide (LPS).

\section{MATERIALS AND METHODS}

Materials. Shekwasha (Citrus depressa) juice concentrate was purchased from Taketombo Co. (Yokohama, Japan). D-Galactosamine hydrochloride and acet- 
aminophen were purchased from Sigma-Aldrich (St. Louis, MO, USA). Lipopolysaccharide from Escherichia coli 055 , carbon tetrachloride and the other chemical reagents and solvents were purchased from Wako Pure Chemical Industries, Ltd. (Osaka, Japan). Silica gel for column chromatography (Kieselgel 60) and silica gel plates for thin-layer chromatography (Kieselgel F254) were purchased from Merck KGaA (Darmstadt, Germany). Casein was purchased from Nacalai Tesque, Inc. (Kyoto, Japan). Mineral and vitamin mixtures (AIN-93) and cellulose powder were purchased from Oriental Yeast Co., Ltd. (Tokyo, Japan), and the other ingredients of the diet were from Wako.

General procedures. ${ }^{1} \mathrm{H}$-nuclear magnetic resonance (NMR) spectra (one-dimensional) were recorded on a JEOL lambda-500 spectrometer at $500 \mathrm{MHz}$. The spectra of electrospray ionization mass spectrometry (ESIMS) were measured on a JMS-T100LC mass spectrometer. Separations by high-performance liquid chromatography (HPLC) were performed with a JASCO Gulliver system using preparative columns (Develosil C30-UG-5, Nomura Chemistry, Seto, Japan; Senshu PAK AQ, Senshu Chemistry, Tokyo, Japan; Cosmosil HILIC WATERS, Nacalai Tesque).

Extraction and isolation of active compound from shekwasha. Shekwasha juice was successively extracted with $n$-hexane and ethyl acetate (EtOAc), giving three fractions (fractions I-III). Fraction I was applied on a silica gel open column $(8 \times 57.5 \mathrm{~cm})$ and eluted successively with $n$-hexane/EtOAc $(10: 0,9: 1,8: 2$, $7: 3,6: 4,5: 5$ and $0: 10$, vol/vol) and methanol, giving five relatively major compounds (compounds 1-5). These compounds were purified by silica gel column chromatography with a smaller open column $(3 \times 30 \mathrm{~cm})$ and finally purified by preparative HPLC).

Animals and diets. In this study, five separate animal experiments were conducted to assess liver injury-suppressing effect. Six-week-old male rats of the Wistar strain (120-130 g) were purchased from Japan SLC, Inc. (Hamamatsu, Japan). The rats were individually housed in hanging stainless steel wire cages kept in a room at a controlled temperature $\left(23-25^{\circ} \mathrm{C}\right)$ and humidity (50-60\%). Lights were maintained on a $12 \mathrm{~h}$ light-dark cycle (lights on from 7:00 to 19:00). The rats were acclimated to the facility for 4-5 $\mathrm{d}$ and given free access to water and the control diet. The composition of the control diet was as follows (\%): casein, 25; cornstarch, 43.25; sucrose, 20; corn oil, 5; mineral mixture (AIN-93G), 3.5; vitamin mixture (AIN-93), 1; choline bitartrate, 0.25; and cellulose, 2. When supplements were added to the diet, cornstarch was reduced to make $100 \%$. After adaptation to the control diet, rats were divided into groups and allowed free access to water and the control diet or experimental diets.

In experiment 1 , rats were fed the control diet or diet supplemented with a powder of lyophilized shekwasha juice at a level of $10 \%$ for $7 \mathrm{~d}$. In experiment 2 , rats were fed the control diet or diets supplemented with each fraction (fractions I, II and III) derived from solvent extraction of shekwasha juice at levels comparable to the addition of lyophilized shekwasha juice at a $10 \%$ level (fraction I, $0.096 \%$; fraction II, $0.435 \%$; fraction III, 9.469\%) for $7 \mathrm{~d}$. The addition levels of fractions I, II and III were based on the fact that lyophilized shekwasha juice was composed of $0.96 \%$ fraction I, $4.35 \%$ fraction II and $94.69 \%$ fraction III. In experiment 3, rats were fed the control diet for $7 \mathrm{~d}$ and each compound was singly force-fed to rats at a level of $300 \mathrm{mg} /$ $\mathrm{kg}$ body wt $4 \mathrm{~h}$ before the injection of GalN. In experiment 4 , rats were fed the control diet for $7 \mathrm{~d}$ and compound 4 (nobiletin) was singly force-fed at a graded levels $(25,50,100$ and $200 \mathrm{mg} / \mathrm{kg}$ body wt) $4 \mathrm{~h}$ before the injection of GalN. In experiment 5, rats were fed the control diet for $7 \mathrm{~d}$ and compound 4 (nobiletin) was singly force-fed $4 \mathrm{~h}$ before the treatment with carbon tetrachloride, APAP or GalN+LPS to test whether compound 4 (nobiletin) had a suppressive effect on liver injury other than that by GalN. In experiments 3, 4 and 5 , test compounds were suspended in $0.5 \%$ methylcellulose solution and force-fed to rats with a stomach tube. After $7 \mathrm{~d}$ of feeding the experimental diets (experiments 1 and 2 ) or after $4 \mathrm{~h}$ of the administration of test samples (experiments 3, 4 and 5), rats were intraperitoneally injected with GalN, which was neutralized with $\mathrm{NaOH}$, at a dose of $350 \mathrm{mg} / \mathrm{kg}$ of body wt according to our previous study (2) between 10:00 and 11:00 (experiments 1 and 2) or 14:00 and 15:00 (experiments 3, 4 and 5). In experiment 5-A, rats were orally administered carbon tetrachloride, which was dissolved in olive oil, at a level of $1.5 \mathrm{~mL} / \mathrm{kg}$ body wt between 14:00 and 15:00. In experiment 5-B, rats were intraperitoneally injected with APAP, which was dissolved in $0.5 \%$ methylcellulose solution, at a level of $800 \mathrm{mg} / \mathrm{kg}$ body wt. In experiment 5-C, rats were intraperitoneally injected with a mixture of GalN+LPS at levels of $200 \mathrm{mg} / \mathrm{kg}$ and $10 \mu \mathrm{g} / \mathrm{kg}$ for GalN and LPS, respectively. Normal rats were treated with saline or olive oil.

At $24 \mathrm{~h}$ after the treatment with GalN or other drugs except for experiment 5-C, rats were killed by decapitation to obtain blood and liver. In experiment 5-C, rats were killed at $8 \mathrm{~h}$ after the treatment with GalN/LPS to assess the magnitude of liver injury and at $1 \mathrm{~h}$ after the treatment with the drugs to measure plasma tumor necrosis factor (TNF)- $\alpha$ concentration. The latter dissection time $(1 \mathrm{~h})$ was determined by our previous result that plasma TNF- $\alpha$ concentration increased maximally at around $1 \mathrm{~h}$ after treatment with GalN/LPS (3). Rats were not starved either before or after the treatment with drugs. This study was approved by the Animal Use Committee of Shizuoka University, and the animals were maintained in accordance with guidelines for the care and use of laboratory animals, Shizuoka University.

Biochemical analysis. To assess the magnitude of liver injury, the activities of plasma alanine aminotransferase (ALT) and aspartate aminotransferase (AST) were measured with a kit (Transaminase C II-Test; Wako). In experiment $5-\mathrm{C}$, some variables concerning liver injury were also measured. Plasma TNF- $\alpha$ concentration at $1 \mathrm{~h}$ after the treatment with GalN/LPS was 
Table 1. Effect of dietary addition of shekwasha at a $10 \%$ level on D-galactosamine-induced liver injury in rats (Expt. 1).

\begin{tabular}{lccc}
\hline & \multicolumn{3}{c}{ Group } \\
\cline { 2 - 4 } & Normal & Control & Shekwasha \\
\hline Body wt gain, g/7 d & $31 \pm 1$ & $30 \pm 1$ & $30 \pm 2$ \\
Food intake, g/7 d & $93 \pm 3^{\mathrm{b}}$ & $93 \pm 2^{\mathrm{b}}$ & $108 \pm 2^{\mathrm{a}}$ \\
Liver wt, \% of body wt 3.65 0.13 & $3.65 \pm 0.05$ & $3.58 \pm 0.04$ \\
Plasma enzyme activity: & & \\
ALT, mmol/min/L & $0.04 \pm 0.01^{\mathrm{c}}$ & $4.71 \pm 0.34^{\mathrm{a}}$ & $2.09 \pm 0.41^{\mathrm{b}}$ \\
AST, mmol/min/L & $0.14 \pm 0.01^{\mathrm{c}}$ & $10.44 \pm 0.65^{\mathrm{a}}$ & $4.95 \pm 0.86^{\mathrm{b}}$
\end{tabular}

${ }^{1}$ Each value is the mean \pm SE, $n=5$ (normal) or 10 (the other groups). Values with different letters are significantly different at $p<0.05$. ALT, alanine aminotransferase; AST, aspartate aminotransferase.

measured with TNF- $\alpha$ ELISA Kit (Cosmo Bio, Tokyo, Japan). Plasma NO concentration at $8 \mathrm{~h}$ after the treatment with drugs was measured with $\mathrm{NO}_{2} / \mathrm{NO}_{3}$ Assay Kit (Dojin Laboratories, Kumamoto, Japan). Hepatic DNA fragmentation was detected by agarose gel electrophoresis and quantified with DNA ELISA Kit (Boehringer Mannheim, Mannheim, Germany) as described previously (3). The amount of mRNA for inducible nitric oxide synthase (iNOS) relative to the amount of mRNA for $\beta$-actin in the liver was measured by quantitative real-time PCR analysis as described previously (4), where the validated probe and primer for iNOS (assay identification number: Rn00561646_m1) were pre-designated TaqMan Gene Expression Assay products (Applied Biosystems, Foster City, CA).

Statistical analysis. Results were expressed as mean \pm standard error of mean (SE). Data were analyzed by a one-way analysis of variance. The difference between mean values was tested by the Tukey test when the $F$ value was significant. A $p$ value of 0.05 or less was considered significant. The statistical analysis was performed using Mac Toukei-Kaiseki ver 1.5 software (Esumi, Tokyo, Japan).

\section{RESULTS}

Effects of dietary addition of shekwasha juice on D-galactosamine-induced liver injury (experiment 1)

Dietary addition of lyophilized shekwasha juice at a level of $10 \%$ did not affect the body weight gain of rats during the 7-d experimental period, whereas it slightly increased food intake (Table 1). The relative liver weight did not differ among the groups. The plasma ALT and AST activities were significantly increased by GalN injection and these increases were significantly suppressed by dietary addition of shekwasha.

Fractionation and isolation of active compounds from shekwasha (experiments 2, 3 and 4)

Shekwasha juice was extracted with $n$-hexane, and the residue was further extracted with EtOAc, giving three fractions (fractions I, II and III) (Fig. 1). The yield of fraction I or II was far smaller than that of fraction

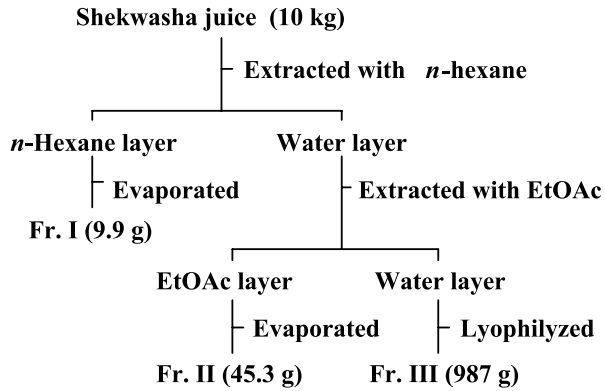

Fig. 1. Fractionation of shekwasha juice by successive extraction with organic solvents and the yields of each fraction. The shekwasha juice contained dry matter at a level of $1,042 \mathrm{~g} / 10 \mathrm{~kg}$.
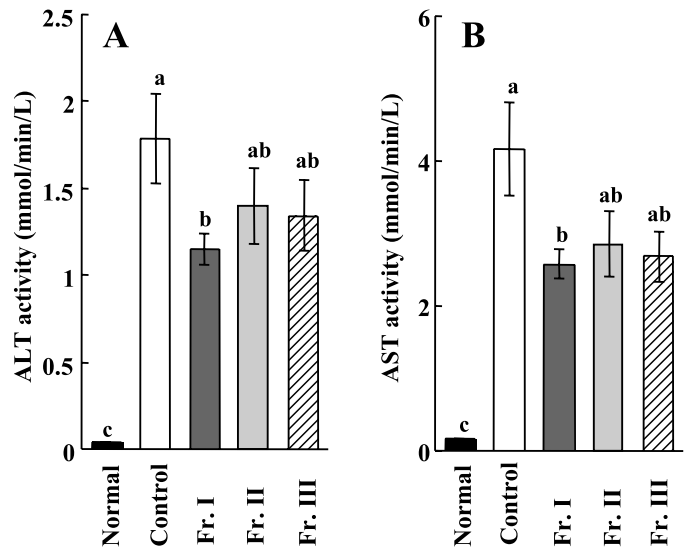

Fig. 2. Effects of dietary addition of fractions I to III from shekwasha juice on D-galactosamine-induced increases in plasma alanine aminotransferase (A) and aspartate aminotransferase (B) activities in rats (Expt. 2 ). Each value is the mean \pm SE for 5 (normal) and 10 (the other groups). Values with different letters are significantly different at $p<0.05$. ALT, alanine aminotransferase; AST, aspartate aminotransferase.

III. GalN-induced increases in plasma ALT and AST activities were significantly suppressed by dietary addition of fraction I, but not by fraction II or III (Fig. 2). Since fraction I had a significantly suppressive effect, fraction I was separated by silica gel column chromatography, giving five relatively major compounds (compounds 1-5). The yields of these compounds were $0.137 \%$ (compound 1), $0.089 \%$ (compound 2), $0.112 \%$ (compound 3), $0.238 \%$ (compound 4) and $0.073 \%$ (compound 5) of lyophilized shekwasha juice. To assess the liver injury-suppressing effect, these compounds were singly force-fed to rats $4 \mathrm{~h}$ before the treatment with GalN at a level of $300 \mathrm{mg} / \mathrm{kg}$ body wt, since the amounts of these compounds obtained were limited. GalN-induced increases in plasma ALT and AST activities were significantly suppressed by compounds 2,3 and 4, but not by compound 1 or 5 (Fig. 3). It should be noted that three rats of the total seven rats fed compound 4 died within $24 \mathrm{~h}$ after the treatment with GalN. The structures of the five compounds were analyzed by ESI-MS and NMR. Compound 2: ESI-MS (positive); $m / z 427$ (M+Na). ${ }^{1} \mathrm{H}-\mathrm{NMR}$ (in $\mathrm{CD}_{3} \mathrm{OD}$ ); $2.88(2 \mathrm{H}$, 

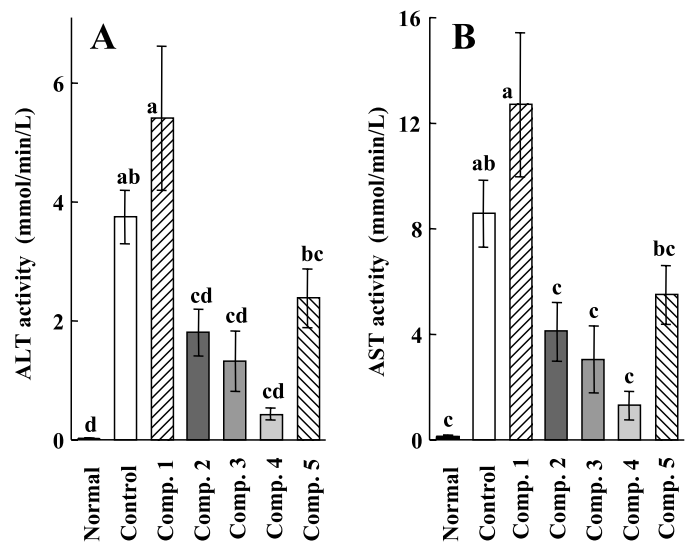

Fig. 3. Effects of force-feeding of compounds 1 to 5 from fraction I at a level of $300 \mathrm{mg} / \mathrm{kg}$ body weight on D-galactosamine-induced increases in plasma alanine aminotransferase (A) and aspartate aminotransferase (B) activities in rats (Expt. 3). Each value is the mean \pm SE for 5 (normal), 10 (control) and 7 (the other groups). Values with different letters are significantly different at $p<0.05$. ALT, alanine aminotransferase; AST, aspartate aminotransferase.

2<smiles>COc1ccc(C2CC(=O)c3c(OC)c(OC)c(OC)c(OC)c3O2)cc1OC</smiles><smiles>COC1=C(OC)C2OC(c3ccc(OC)cc3)CC(=O)C2C(OC)=C1OC</smiles>

4<smiles>COc1ccc(-c2cc(=O)c3c(OC)c(OC)c(OC)c(OC)c3o2)cc1OC</smiles>

Fig. 4. Structures of compounds 2, 3 and 4 .

dd, $J=17,3 \mathrm{~Hz}, \mathrm{H}-3), 3.78$ (3H, s, H-6), 3.78 (3H, s, H7), 3.83 (3H, s, H-3'), 3.84 (3H, s, H-4'), 3.84 (3H, s, H5), 3.99 (3H, s, H-8), $5.33(1 \mathrm{H}, \mathrm{d}, J=13 \mathrm{~Hz}, \mathrm{H}-2), 6.83$ $\left(1 \mathrm{H}, \mathrm{d}, J=8 \mathrm{~Hz}, \mathrm{H}-5^{\prime}\right), 6.94\left(2 \mathrm{H}, \mathrm{d}, J=8 \mathrm{~Hz}, \mathrm{H}-2^{\prime}, 6^{\prime}\right)$. Compound 3: ESI-MS (positive); $m / z 395(\mathrm{M}+\mathrm{Na}) .{ }^{1} \mathrm{H}-$ NMR (in $\mathrm{CD}_{3} \mathrm{OD}$ ); 3.76 (3H, s, H-4'), 3.85 (3H, s, H-6), 3.85 (3H, s, H-7), 3.92 (3H, s, H-5), 4.00 (3H, s, H-8), $6.48(1 \mathrm{H}, \mathrm{s}, \mathrm{H}-3), 6.89$ (2H, d, J=9 Hz, H-3',5'), 7.75 $\left(2 \mathrm{H}, \mathrm{d}, J=9 \mathrm{~Hz}, \mathrm{H}-2^{\prime}, 6^{\prime}\right)$. Compound 4: ESI-MS (positive); $m / z 425$ (M+Na). ${ }^{1} \mathrm{H}-\mathrm{NMR}$ (in $\mathrm{CD}_{3} \mathrm{OD}$ ); 3.91 (3H, s, H-6), 3.91 (3H, s, H-7), 3.92 (3H, s, H-3'), 3.94 (3H, s, H-4'), 3.99 (3H, s, H-5), 4.07 (3H, s, H-8), 6.59 (1H,
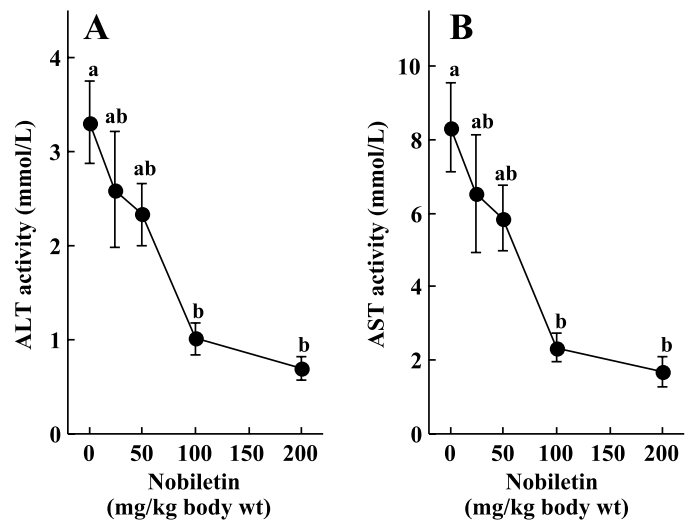

Fig. 5. Dose-dependent effect of compound 4 (nobiletin) on D-galactosamine-induced increases in plasma alanine aminotransferase (A) and aspartate aminotransferase (B) activities in rats (Expt. 4). Each value is the mean \pm SE for 5 (normal), 10 (control) and 6 (the other groups). Values with different letters are significantly different at $p<0.05$. Nobiletin was orally administered at levels of 25, 50, 100 and $200 \mathrm{mg} / \mathrm{kg}$ body $\mathrm{wt}$ $4 \mathrm{~h}$ before treatment with D-galactosamine. ALT, alanine aminotransferase; AST, aspartate aminotransferase.

Table 2. Effects of nobiletin on liver injury induced by carbon tetrachloride, acetaminophen or D-galactosamine+lipopolysaccharide in rats (Expt. 5). ${ }^{1}$

Plasma enzyme activity $(\mathrm{mmol} / \mathrm{min} / \mathrm{L})$

\begin{tabular}{lcr} 
& \multicolumn{1}{c}{ ALT } & \multicolumn{1}{c}{ AST } \\
\hline A. CCl -induced liver injury & \\
Normal & $0.03 \pm 0.00^{\mathrm{b}}$ & $0.14 \pm 0.01^{\mathrm{b}}$ \\
Control & $4.32 \pm 0.51^{\mathrm{a}}$ & $8.72 \pm 1.15^{\mathrm{a}}$ \\
Nobiletin $^{2}$ & $1.12 \pm 0.15^{\mathrm{b}}$ & $2.40 \pm 0.33^{\mathrm{b}}$ \\
B. APAP-induced liver injury & \\
Normal & $0.04 \pm 0.00^{\mathrm{b}}$ & $0.14 \pm 0.01^{\mathrm{b}}$ \\
Control & $3.29 \pm 0.44^{\mathrm{a}}$ & $15.79 \pm 2.45^{\mathrm{a}}$ \\
Nobiletin & $0.87 \pm 0.31^{\mathrm{b}}$ & $3.13 \pm 1.13^{\mathrm{b}}$ \\
C. GalN/LPS-induced liver injury & \\
Normal & $0.04 \pm 0.00^{\mathrm{b}}$ & $0.14 \pm 0.01^{\mathrm{b}}$ \\
Control $_{\text {Nobiletin }}$ & $4.16 \pm 0.59^{\mathrm{a}}$ & $12.15 \pm 1.74^{\mathrm{a}}$ \\
& $0.83 \pm 0.19^{\mathrm{b}}$ & $2.32 \pm 0.50^{\mathrm{b}}$
\end{tabular}

${ }^{1}$ Each value is the mean \pm SE, $n=5$ (normal) or 10 (the other groups). Values with different letters are significantly different at $p<0.05$. ALT, alanine aminotransferase; APAP, acetaminophen; AST, aspartate aminotransferase; GalN, D-galactosamine; LPS, lipopolysaccharide.

${ }^{2}$ Administered orally at a level of $100 \mathrm{mg} / \mathrm{kg}$ body wt $4 \mathrm{~h}$ before treatment with drugs.

s, H-3), 6.95 (1H, d, J=9 Hz, H-5'), 7.37 (1H, s, H-2'), $7.53\left(1 \mathrm{H}, \mathrm{d}, J=9 \mathrm{~Hz}, \mathrm{H}-6^{\prime}\right)$. These data showed that active compound 2 was a known $3^{\prime}, 4^{\prime}, 5,6,7,8$-hexamethoxyflavanone (citromitin) (5, 6), and compounds 3 and 4 were known $4^{\prime}, 5,6,7,8$-pentamethoxyflavone (tangeretin) $(7,8)$ and $3^{\prime}, 4^{\prime}, 5,6,7,8$-hexamethoxyflavone (nobiletin) $(8,9)$, respectively (Fig. 4). A single force-feeding of nobiletin at levels of 25, 50, 100 and 

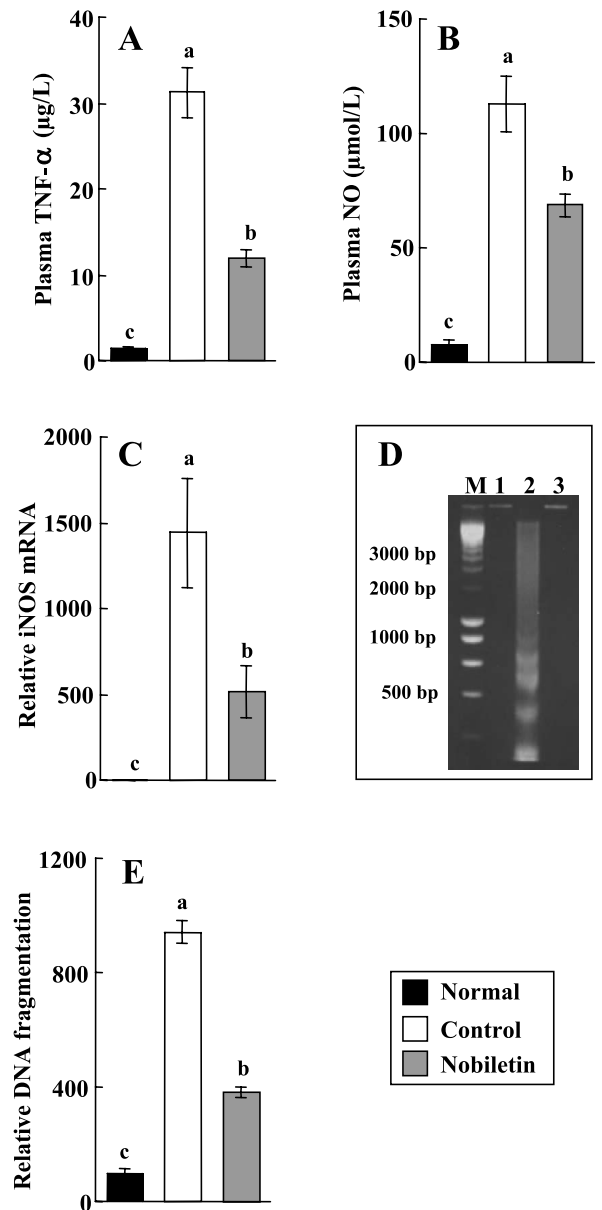

Fig. 6. Effects of compounds 4 (nobiletin) on D-galactosamine/lipopolysaccharide-induced increases in plasma tumor necrosis factor- $\alpha$ (A) and nitric oxide (B) concentrations, hepatic levels of mRNA for inducible nitric oxide synthase (C), DNA ladder pattern (D) and DNA fragmentation (E) in rats (Expt. 5). Each value is the mean \pm SE for 5 (normal) or 10 (the other groups). Values with different letters are significantly different at $p<0.05$. Nobiletin was orally administered at a level of $100 \mathrm{mg} / \mathrm{kg}$ body wt $4 \mathrm{~h}$ before treatment with drugs. In panel $C$, values represent iNOS mRNA/ $\beta$-actin mRNA. In panel D, values represent percent of normal group. iNOS, inducible nitric oxide synthase; NO, nitric oxide; TNF- $\alpha$, tumor necrosis factor- $\alpha$.

$200 \mathrm{mg} / \mathrm{kg}$ body wt dose-dependently suppressed GalNinduced increases in plasma ALT and AST activities, although the effect of the compound was not significant at doses up to $50 \mathrm{mg} / \mathrm{kg}$ (Fig. 5). The dose levels of $\mathrm{IC}_{50}$ were estimated to be $72 \mathrm{mg} / \mathrm{kg}$ for ALT activity and $75 \mathrm{mg} / \mathrm{kg}$ for AST activity.

Effects of nobiletin on different types of liver injury (experiment 5)

The effects of nobiletin, the most abundant substance and the one tending to have the strongest effect, on liver injury induced by carbon tetrachloride, APAP or GalN/ LPS were investigated. The increases in plasma ALT and AST activities caused by these drugs were significantly suppressed when nobiletin was singly force-fed $4 \mathrm{~h}$ before the treatment with drugs at a level of $100 \mathrm{mg} / \mathrm{kg}$ body wt (Table 2 ). In experiment 5-C, several other vari- ables were measured to analyze the mechanism(s) by which nobiletin suppressed GalN/LPS-induced liver injury. The increase in plasma TNF- $\alpha$ at $1 \mathrm{~h}$ after treatment with GalN/LPS was significantly suppressed by nobiletin (Fig. 6A). The increases in plasma NO concentration and the amount of mRNA for iNOS in the liver at $8 \mathrm{~h}$ after treatment with the drugs were also significantly suppressed by nobiletin (Fig. 6B and C). DNA ladder and DNA fragmentation were measured as markers of apoptosis of liver cells following GalN/LPS-induced liver injury. Treatment with GalN/LPS caused a representative ladder pattern of liver oligonucleosomal DNA on agarose gel electrophoresis in control rats, and this DNA ladder was suppressed in rats force-fed with nobiletin (Fig. 6D). Quantitative determination of DNA fragmentation also showed that nobiletin suppressed GalN/ LPS-induced DNA fragmentation in the liver (Fig. 6E).

\section{DISCUSSION}

The present study confirmed the result of our previous study that shekwasha juice had a suppressive effect on GalN-induced liver injury in rats. Based on this confirmation, we attempted to isolate the active compound(s) from the shekwasha juice. The results clearly showed that polymethoxy flavonoids such as citromitin (polymethoxy flavanone), tangeretin (polymethoxy flavone) and nobiletin (polymethoxy flavone) participated in the suppressive effect of shekwasha on GalN-induced liver injury, although the magnitude of the effects of these compounds varied. Early studies have shown that citromitin exists in some species of citrus $(5,6)$, but to our knowledge little biological effect of the compound has been demonstrated. On the other hand, there are a number of reports concerning a variety of biological effects of tangeretin and nobiletin, especially nobiletin, in addition to the concentrations of polymethoxy flavones in various species of citrus $(10,11)$. For instances, direct and indirect evidences have been provided for anti-cancer effects (12-20), anti-inflammatory effects (21-24), inhibition of NO production (25, 26), enhancement of differentiation and lipolysis of adipocytes (27), prevention of cartilage destruction (28), improvement of memory impairment (29) and neurodegradation (30). However, no liver injury-suppressive effect of tangeretin and nobiletin has been reported yet. So, we report here for the first time that polymethoxy flavonoids (citromitin, tangeretin and nobiletin) have hepatoprotective effects.

Various types of drugs have been used to induce experimental liver injury. GalN is one such drug and has often been used to screen hepatoprotective foods, medicines or their constituents. We have demonstrated that GalN-induced liver injury was effectively suppressed by green tea (31-33), mushrooms (34), fruits (2), and dietary fibers (33) in rats. It has been thought that GalN induces liver injury by inhibiting the synthesis of RNA and proteins through a decrease in hepatic UTP concentration, which finally evokes the necrosis of liver cells (35-37), although recent reports have suggested that several cytokines, e.g., interleukin (IL)- $1 \alpha$ 
(38), IL-6 (39) and IL-18 (40), and NO (41) might also participate in the pathogenesis of GalN-induced liver injury. It is thought that oxidative stress is associated with liver injury caused by carbon tetrachloride or APAP, as shown by the fact that carbon tetrachloride gives rise to free radical such as carbon trichloride radical and APAP exhausts reduced glutathione in the liver $(42,43)$. On the other hand, GalN/LPS is thought to induce liver injury by increasing the production of inflammatory cytokines, as represented by TNF- $\alpha$, and NO through the activation of Kupffer cells by LPS (44, 45). The GalN/LPS-induced prominent liver injury causes excessive apoptosis of liver cells and thereby leads to widespread necrosis (46). One of the most important findings of the present study is that nobiletin had suppressive effects on various types of liver injury. In the present study, we measured several variables related to the pathogenesis of GalN/LPS-induced liver injury, since mediators in the pathogenesis of GalN/ LPS-induced liver injury are relatively obvious as described above. The results obtained here suggest that nobiletin elicits its suppressive effect on GalN/LPSinduced liver injury at least by suppressing the production of both TNF- $\alpha$ and NO. It was also demonstrated that nobiletin suppressed the gene expression of iNOS and comprehensive apoptosis of liver cells. On the other hand, the detailed mechanisms by which shekwasha or its active compounds elicit their suppressive effect on liver injuries induced by GalN, carbon tetrachloride and APAP are currently uncertain.

There are a number of reports concerning the liver injury-suppressive effects of several types of flavonoids other than citromitin, tangeretin and nobiletin. For instance, the suppressive effects of glycosidic flavone and flavonols from green tea on GalN-induced liver injury (33), baicaline on APAP- (47) or GalN/LPSinduced liver injury (48), glycosidic flavone from rice on carbon tetrachloride-induced liver injury (49), hesperidin on LPS-induced liver injury (50), and methoxy flavone and luteoline from Cleome droserifolia on carbon tetrachloride-induced liver injury (51) have been shown. These previous studies appear to support the concept that certain types of flavonoids might exhibit hepatoprotective effects regardless of the type of liver injury. In humans, viruses, chemicals, medicines, alcohol, autoimmune diseases, etc. cause liver injury or hepatitis, and hepatitis induced by viruses is predominant in Asian countries (52). In Japan, shekwasha juice has often been used to dilute alcoholic drinks that contain relatively high levels of alcohol. So, it is highly interesting to know whether shekwasha juice or its constituents can prevent alcohol-induced liver injury as well as virus-induced hepatitis, but this remains to be further clarified.

It should be noted that nobiletin exhibited a lethal effect on several rats when the compound was singly force-fed to rats at a level of $300 \mathrm{mg} / \mathrm{kg}$ body wt (experiment 3). However, the lethal effect of nobiletin was not detected up to the dose of $200 \mathrm{mg} / \mathrm{kg}$ (experiment 4), suggesting that nobiletin might be safe below the dose level of $200 \mathrm{mg} / \mathrm{kg}$. It is unclear whether the lethal effect is ascribed to nobiletin itself or the combination of nobiletin and GalN. The intake of nobiletin in rats fed a diet containing $10 \%$ lyophilized shekwasha juice is estimated to be about $25 \mathrm{mg} / \mathrm{kg} / \mathrm{d}$, a dose level one order lower than the dose level that caused the lethal effect. In addition, dietary addition of lyophilized shekwasha juice at a level of $10 \%$ did not cause any deleterious effects on the growth or food intake of rats. These facts appear to warrant the safety of shekwasha juice itself. On the other hand, the toxicity of citromitin or tangeretin due to excessive administration seems to be smaller than that of nobiletin, since citromitin and tangeretin did not cause such a lethal effect at a dose of $300 \mathrm{mg} /$ $\mathrm{kg}$. Information concerning the safety of nobiletin is limited. Delaney et al. (53) have reported that a citrus polymethoxy flavone mixture, which contained nobiletin at a level of $30.7 \%$, caused a mild suppression of natural killer cell activity when the mixture was administered by gavage at a higher level $(500 \mathrm{mg} / \mathrm{kg})$, whereas the mixture of citrus polymethoxy flavones was not genotoxic in an in vitro system (54). The mechanism underlying the lethal effect of nobiletin at a high level is currently uncertain. It remains to be elucidated by further studies from the viewpoint of confirmation of the safety of citrus.

\section{REFERENCES}

1) Nestle M. 1996. Fruits and vegetables: protective or just fellow travelers? Nutr Rev 54: 255-257.

2) Kawagishi H, Fukumoto Y, Hatakeyama M, He P, Arimoto H, Matsuzawa T, Arimoto Y, Suganuma H, Inakuma T, Sugiyama K. 2001. Liver injury suppressing compounds from avocado (Persea americana). J Agric Food Chem 49: 2215-2221.

3) He P, Noda Y, Sugiyama K. 2001. Green tea suppresses lipopolysaccharide-induced liver injury in D-galactosamine-sensitized rats. J Nutr 131: 1560-1567.

4) Ohuchi S, Morita T, Mori M, Sugiyama K. 2009. Hepatic cystathionine $\beta$-synthase activity does not increase in response to methionine supplementation in rats fed a low casein diet: association with plasma homocysteine concentrations. J Nutr Sci Vitaminol 55: 178-185.

5) Sastry GP, Row LR. 1961. Chemical investigation of Citrus mitis Blanko-III: isolation of two new flavanones. Tetrahedron 15: 111-114.

6) Chaliha BP, Sastry GP, Rao PR. 1967. Chemical investigation of Citrus reticulata Blanko. Indian J Chem 5: 239240.

7) Mak NK, Wong-Leung YL, Chan SC, Wen J, Leung KN, Fung MC. 1996. Isolation of anti-leukemia compounds from Citrus reticulata. Life Sci 58: 1269-1276.

8) Wang D, Wang J, Huang X, Tu Y, Ni K. 2007. Identification of polymethoxylated flavones from green tangerine peel (Pericarpium Citri Reticulate Viride) by chromatographic and spectroscopic techniques. J Pharm Biomed Anal 44: 63-69.

9) Li S, Yu H, Ho CT. 2006. Nobiletin: efficient and large quantity isolation from orange peel extract. Biomed Chromatogr 20: 133-138.

10) Nogata Y, Sakamoto K, Shiratsuchi H, Ishii T, Yano M, Ohta H. 2006. Flavonoid composition of fruit tissues of citrus species. Biosci Biotechnol Biochem 70: 178-192. 
11) Green CO, Wheatley AO, Osagie AU, St A Morrison EY, Asemota HN. 2007. Determination of polymethoxylated flavones in peels of selected Jamaican and Mexican citrus (Citrus spp.) cultivars by high-performance liquid chromatography. Biomed Chromatogr 21: 48-54.

12) Murakami A, Nakamura $Y$, Torioka $K$, Tanaka $T$, Koshiba T, Koshimizu K, Kuwahara S, Takahashi Y, Ogawa K, Yano M, Tokuda H, Nishino H, Mimaki Y, Sashida Y, Kitanaka S, Ohihashi H. 2000. Inhibitory effect of citrus nobiletin on phorbol ester-induced skin inflammation, oxidative stress, and tumor promotion in mice. Cancer Res 60: 5059-5066.

13) Kohno H, Yoshitani S, Tsukio Y, Murakami A, Koshimizu K, Yano M, Tokuda H, Nishino H, Ohigashi H, Tanaka T. 2001. Dietary administration of citrus nobiletin inhibits azoxymethane-induced colonic aberrant crypt foci in rats. Life Sci 69: 901-913.

14) Sato T, Koike L, Miyata Y, Hirata M, Mimaki Y, Sashida $Y$, Yano M, Ito A. 2002. Inhibition of activator-1 binding activity and phosphatidylinositol 3-kinase pathway by nobiletin, a polymethoxy flavonoid, results in augmentation of tissue inhibitor of metalloproteinase-1 production and suppression of protection of matrix metalloproteinase-1 and -9 in human fibrosarcoma HT-1080 cells. Cancer Res 62: 1025-1029.

15) Morley K, Ferguson PJ, Koropatnick J. 2007. Tangeretin and nobiletin induce G1 cycle arrest but not apoptosis in human breast and colon cancer cells. Cancer Lett 251: 168-178.

16) Tang M, Ogawa K, Asamoto M, Hokaiwado N, Seeni A, Suzuki S, Takahashi S, Tanaka T, Ichikawa K, Shirai T. 2007. Protective effects of citrus nobiletin and auraptene in transgenic rats developing adenocarcinoma of the prostate (TRAP) and human prostate carcinoma cells. Cancer Sci 98: 471-477.

17) Miyata Y, Sato T, Imada K, Dobashi A, Yano M, Ito A. 2008. A citrus polymethoxyflavonoid, nobiletin, is a novel MEK inhibitor that exhibits antitumor metastasis in human fibrosarcoma HT-1080 cells. Biochem Biophys Res Commun 366: 168-173.

18) Miyamoto S, Yasui Y, Tanaka T, Ohigashi H, Murakami A. 2008. Suppressive effects of nobiletin on hyperleptinemia and colitis-related colon carcinogenesis in male ICR mice. Carcinogenesis 29: 1057-1063.

19) Akao Y, Itoh T, Ohguchi K, Iinuma M, Nozawa Y. 2008. Interactive effects of polymethoxy flavones from citrus on cell growth inhibition in human neuroblastoma SHSY5Y cells. Bioorg Med Chem Lett 16: 2803-2810.

20) Luo G, Guan X, Zhou L. 2008. Apoptic effect of citrus fruit extract nobiletin on lung cancer cell line A549 in vitro and in vivo. Cancer Biol Ther 7: 966-973.

21) Lin N, Sato T, Takayama Y, Mimaki Y, Sashida Y, Yano M, Ito A. 2003. Novel anti-inflammatory actions of nobiletin, a citrus polymethoxy flavonoid, on human synovial fibloblasts and mouse macrophages. Biochem Pharmacol 65: 2065-2071.

22) Tanaka S, Sato T, Akimoto N, Yano M, Ito A. 2004. Prevention of UVB-induced photoinflammation and photoaging by a polymethoxy flavonoid, nobiletin, in human keratinocytes in vivo and in vitro. Biochem Pharmacol 68: $433-439$.

23) Murakami A, Shigemori T, Ohigashi H. 2005. Zingiberaceous and citrus constituents, 1 '-acetoxychavicol acetate, zerumbone, auraptene, and nobiletin, suppress lipopolysaccharide-induced cyclooxygenase-2 expres- sion in RAW264.7 murine macrophages through different modes of action. J Nutr 135: 2987S-2992S.

24) Choi S, Hwang J, Ko H, Park J, Kim S. 2007. Nobiletin from citrus fruit peel inhibits the DNA-binding activity of NF- $\kappa \mathrm{B}$ and ROS production in LPS-activated RAW264.7 cells. J Ethnopharmacol 113: 149-155.

25) Choi S, Ko H, Ko S, Hwang J, Park J, Kang S, Hsan S, Yun S, Kim S. 2007. Correlation between flavonoid content and the NO production inhibitory activity of peel extracts from various citrus fruits. Bull Pharm Bull 30: $772-778$.

26) Li S, Sang S, Pan M, Lai C, Lo C, Yang C, Ho C. 2007. Anti-inflammatory property of the urinary metabolites of nobiletin in mouse. Bioorg Med Chem Lett 17: 51775181.

27) Saito T, Abe D, Sekiya K. 2007. Nobiletin enhances differentiation and lipolysis of 3T3-L1 adipocytes. Biochem Biophys Res Commun 357: 371-376.

28) Imada K, Lin N, Liu C, Lu A, Chen W, Yano M, Sato T, Ito A. 2008. Nobiletin, a citrus polymethoxy flavonoid, suppresses gene expression and production of aggrecanases-1 and -2 in collagen-induced arthritic mice. Biochem Biophys Res Commun 373: 181-185.

29) Nakajima A, Yamakuni T, Matsuzaki K, Nakata N, Onozuka H, Yokosuka A, Sashida Y, Mimaki Y, Ohizumi Y. 2007. Nobiletin, a citrus flavonoid, reverses learning impairment associated with $\mathrm{N}$-methyl-D-aspartate receptor antagonism by activation of extracellular signal-regulated kinase signaling. J Pharmacol Exp Ther 321: 784-790.

30) Nakajima A, Yamakuni T, Haraguchi M, Omae N, Song S, Kato C, Nakagawasai O, Tadano T, Yokosuka A, Mimaki Y, Sashida Y, Ohizumi Y. 2007. Nobiletin, a citrus flavonoid that improves memory impairment, rescues bulbectomy-induced cholinergic neurodegeneration in mice. J Pharmacol Sci 105: 122-126.

31) Sugiyama K, He P, Wada S, Tamaki F, Saeki S. 1998. Green tea suppresses D-galactosamine-induced liver injury in rats. Biosci Biotechnol Biochem 62: 609-611.

32) Sugiyama K, He P, Wada S, Saeki S. 1999. Teas and other beverages suppress D-galactosamine-induced liver injury in rats. J Nutr 129: 1361-1367.

33) Wada S, He P, Hashimoto N, Watanabe N, Sugiyama K. 2000. Glycosidic flavonoids as rat liver injury-preventing compounds from green tea. Biosci Biotechnol Biochem 64: 2260-2263.

34) Lee EW, He P, Kawagishi H, Sugiyama K. 2000. Suppression of D-galactosamine-induced liver injury by mushrooms in rats. Biosci Biotechnol Biochem 64: 2001-2004.

35) Keppler D, Lesch R, Reutter W, Decker K. 1968. Experimental hepatitis induced by D-galactosamine. Exp Mol Pathol 9: 279-290.

36) Shinozuka H, Farber JL, Konishi Y, Anukarahanonta T. 1973. D-Galactosamine and acute liver cell injury. Fed Proc 32: 1516-1526.

37) Decker K, Keppler D. 1974. Galactosamine hepatitis: key role of the nucleotide deficiency period in the pathogenesis of cell injury and cell death. Rev Physiol Biochem Pharmacol 71: 77-106.

38) Lozano JM, Padillo J, Montero JL, Pena J, De la Mata M, Mutane J. 2003. Immunomodulatory activity of TNF- $\alpha$ during acute liver injury induce by D-galactosamine and its protection by PGE1 in rats. Int Immunopharmacol 3: 197-207. 
39) Izu H, Hizume K, Goto K, Hirotsune M. 2007. Hepatoprotective effects of a concentrate and components of sake against galactosamine (GalN)-induced liver injury in mice. Biosci Biotechnol Biochem 71: 951-957.

40) Komano T, Egashira Y, Sanada H. 2008. L-Gln and L-Ser suppress the D-galactosamine-induced IL-18 expression and hepatitis. Biochem Biophys Res Commun 372: 688690.

41) Siendones E, Fouad D, Abou-Elella AM, Quintero A, Barrera P, Muntane J. 2003. Role of nitric oxide in Dgalactosamine-induced cell death and its protection by PGE1 in cultured hepatocytes. Nitric Oxide 8: 133-143.

42) Basu S. 2003. Carbon tetrachloride-induced lipid peroxidation: eicosanoid formation and their regulation by antioxidant nutrients. Toxicology 189: 113-127.

43) James LP, Mayeux PR, Hinson JA. 2003. Acetaminophen-induced hepatotoxicity. Drug Metab Dispos 31: 1499-1506.

44) Bradham CA, Plumpe J, Manns MP, Brenner DA, Trautwein C. 1998. Mechanism of hepatic toxicity. I. TNFinduced liver injury. Am J Physiol 275: G387-G392.

45) Morikawa A, Kato Y, Sugiyama T, Koide N, Chakravortty D, Yoshida T, Yokochi T. 1999. Role of nitric oxide in lipopolysaccharide-induced hepatic injury in D-galactosamine-sensitized mice as an experimental endotoxin shock model. Infect Immun 67: 1018-1024.

46) Leist M, Gantner F, Bohlinger I, Tiegs G, Germann PG, Wendel A. 1995. Tumor necrosis factor-induced hepatocyte apoptosis precedes liver failure in experimental murine shock models. Am J Pathol 146: 1220-1234.

47) Jang SI, Kim HJ, Hwang KM, Jekal SJ, Pae HO, Choi BM,
Yun YG, Kwon TO, Chung HT, Kim YC. 2003. Hepatoprotective effect of baicalin, a major flavone from Scutellaria radix, on acetaminophen-induced liver injury in mice. Immunopharmacol Immunotoxicol 25: 585-594.

48) Wan JY, Gong X, Zhang L, Li HZ, Zhou YF, Zhou QX. 2008. Protective effect of baicalin against lipopolysaccharide/D-galactosamine-induced liver injury in mice by up-regulation of heme oxygenase-1. Eur J Pharmacol 587: 302-308.

49) Xu DH, Mei XT, Chen Y, Li YM, Lv JY, Xu SB. 2005. Protective effects of 5, $4^{\prime}$-dihydoxy-3', $5^{\prime}$-dimethoxy-7-O- $\beta$ D-glucopyranosyl-flavone on experimental hepatic injury. World J Gastroenterol 11: 1764-1768.

50) Kaur G, Tirkey N, Chopra K. 2006. Beneficial effect of hesperidin on lipopolysaccharide-induced hepatotoxicity. Toxicology 226: 152-160.

51) Abdel-Kader MS, Alqasoumi SI, Al-Taweel AM. 2009. Hepatoprotective constituents from Cleome droserifolia. Chem Pharm Bull 57: 620-624.

52) Tunon MJ, Alvarez M, Culebras JM, Gonzlez-Gallego J. 2009. An overview of animal models for investigating the pathogenesis and therapeutic strategies in acute hepatic failure. World J Gastroenterol 15: 3086-3098.

53) Delaney B, Phillips K, Buswell D, Mowry B, Nickels D, Cox D, Wang H, Manthey J. 2001. Immunotoxicity of a standardized citrus polymethoxy flavone extract. Food Chem Toxicol 39: 1087-1094.

54) Delaney B, Phillips K, Vasquez C, Wilson A, Cox D, Wang H, Manthey J. 2002. Genetic toxicity of a standardized mixture of citrus polymethoxylated flavones. Food Chem Toxicol 40: 617-624. 